\title{
Lead poisoning prevention: A community-based participatory research program in Mississippi
}

\author{
Amal K. Mitra ${ }^{1 *}$, Charkarra Anderson-Lewis ${ }^{2}$ \\ ${ }^{1}$ School of Public Health, College of Health Sciences, Jackson State University, Jackson, MS 39213, USA; \\ ${ }^{2}$ School of Health Professions, The University of Southern Mississippi, Hattiesburg, MS 39406, USA
}

\begin{abstract}
Background and objectives: Lead poisoning is a preventable environmental health hazard. Although the prevalence of lead poisoning is declining, the rates are disproportionately high in selected communities. This community-based participatory research (CBPR) program aimed to enhance people's awareness on lead poisoning prevention through community outreach and educational interventions in Mississippi.
\end{abstract}

Methods: Secondary data of 42,372 children obtained from the Mississippi State Department of Health were analyzed to identify the most affected communities in Mississippi. Communitybased outreach and education activities were carried out in the most affected areas to increase population awareness on lead poisonig prevention.

Results: Hands-on training was offered to 25 participants at homebuilding retail stores. Of them, $23(92 \%)$ reported the hands-on training was very useful or useful. Among 91 homebuyers and rental home owners who attended workshops offered by the Neighborhood Association, $90 \%$ mentioned that the training was useful or very useful. An online visual training was given to 220 realtors, and 75 inspectors, contractors, and Do-It-Yourself (DIY) workers. At posttest, $59.4 \%, 67.9 \%, 65.1 \%$ of the realtors, inspectors, contractors and DIY workers ( $n=295$ ) identified soil, car batteries and paint as sources of lead in the environment, respectively. A total of $62.3 \%, 48.1 \%$ and $58.5 \%$, at posttest, identified three complications - behavioral, physical and psychological, respectively. The mean posttest score was significantly higher than the pretest scores $(7.47 \pm 2.07$ vs. $6.60 \pm 1.68, p=0.04$, respectively).

Conclusion: These outreach activities were successful in improving the knowledge of the community people on lead poisoning prevention.

IMC J Med Sci 2021; 15(1): 002

\section{Introduction}

In 2012, the Centers for Disease Control and Prevention (CDC) had lowered the cutoff point of blood lead levels (BLLs) from $10 \mu \mathrm{g} / \mathrm{dL}$ to $5 \mu \mathrm{g} / \mathrm{dL}$, in order to identify children as having lead exposure earlier and parents, doctors, public health officials, and communities to take action sooner [1]. The National Childhood Blood Lead Surveillance Data shows that BLLs remained low, ranging from 2.0\% to $2.4 \%$ from 2012 to 2016 , with a slight increase of the rate to $3.0 \%$ in 2017 in the United States [2] However, based on the prevalence rate, approximately 535,000 of U.S. children are still suffering from lead poisoning [3]. Because of the increased risk of lead poisoning among the people who are exposed to household dust and paint as the source of the lead, living in older homes are potentially at a higher risk of lead contamination [3]. Minority children who reside in pre-1978 housing are at greatest risk for exposure, because

*Correspondence: Amal K. Mitra, Department of Epidemiology and Biostatistics, College of Health Sciences, School of Public Health, Jackson, Mississippi, USA. Email: amal.k.mitra@jsums.edu. 
older housing may contain paint with higher lead content [3]. According to the U.S. Department of Housing and Urban Development (HUD), there are approximately 3.8 million houses or buildings that have children living in them who are potentially being exposed to lead [4]. Nearly half a million U.S. children ages 1 to 5 have BLLs at or above $5 \mu \mathrm{g} / \mathrm{dL}$, at which the $\mathrm{CDC}$ recommends public health actions be taken [5].

Exposure to lead is associated with toxicity that affects almost every organ system of the human body [6]. Long-term exposure to lead can seriously harm a child's health and cause well-documented adverse effects including neurological damage [7], retarded growth and development [8], learning and behavioral abnormalities $[9,10]$, hearing and speech problems $[10,11]$, deficits in cognitive function [12], sleep deficits [13], attention deficiencies, and underperformance in school [13]. Some of the symptoms of lead poisoning, such as cognitive deficits, attention deficiencies, behavioral abnormalities, learning difficulties, and speechlanguage pathologies mimic autism spectrum disorders (ASD), which can create diagnostic challenges and management difficulties of such children [10].

The proposed Healthy People 2030 objectives [14] established the nation's strategy for improving the health and well-being of all citizens, and emphasized to reduce blood lead level in children aged 1-5 years. Because of having no safe level of lead, CDC recommends an urgent need of preventing childhood exposures to lead [5]. Culturally appropriate community based programs are needed for the primary prevention of lead poisoning in "high-risk" communities [15].

To provide a comprehensive effort to educating community people on childhood exposure to lead and lead prevention, we developed a CommunityBased Participatory Research (CBPR) program called Community Lead Awareness Partnership (CLAP) for Healthy Kids in Mississippi. The aims of the program were two-fold: (1) Conduct outreach activities for childhood lead poisoning prevention in "high-risk" areas in Mississippi; and (2) Evaluate effectiveness of a comprehensive lead education and training program in awareness building and practices of the people on lead prevention.

\section{Materials and methods}

Selection of the study population: In order to focus our efforts in the area with the greatest need, we analyzed 42,372 records of children aged $<5$ years in Mississippi. The data were obtained from the Mississippi State Department of Health's Lead Poisoning Prevention and Healthy Homes Program (LPPHHP). Nine out of 82 counties in Mississippi reported $12 \%$ or more of the children tested having high BLL. Those nine "high risk" counties, in order of the highest to the lowest levels of BLL included: Forrest, Oktibbeha, Covington, Coahoma, Greene, Grenada, Pike, Jones, and Yazoo County. The City of Hattiesburg, Mississippi is the largest city in Forrest County which was found to have the highest proportion (ranging from $20 \%$ to $27 \%$ ) of children with high BLL. Therefore, our study was undertaken in the Forrest County.

The CLAP for Healthy Kids project activities targeted the population living in the areas of low-income residences of Forrest County. Fig. 1 shows a map of the census tracts within the City of Hattiesburg and the percentage of low-income residents within those areas. Our project concentrated its activities in those areas with the percentage of low-income residents being $55 \%$ or greater.

Selection of community partners: The CLAP for Healthy Kids Project developed partnership with a number of community organizations and stakeholders in Mississippi. From the very beginning of the study, the community partners were involved in the concept building of the research, in identifiying the community needs, and in developing strategies for the project. The partners included Mississippi State Department of Health, the National Paint and Coatings Association, a local Community Housing Development Organization, Hattiesburg City Government, the Head Start Program, community and faith-based organizations, public schools, kindergartens, home buyers, local contractors and realtors. Representatives from all the partners participated in a Community Advisory Board (CAD). CADs met quarterly to discuss the study activities, the study progress and any problems encountered. CADs also served as an external body to evaluate 


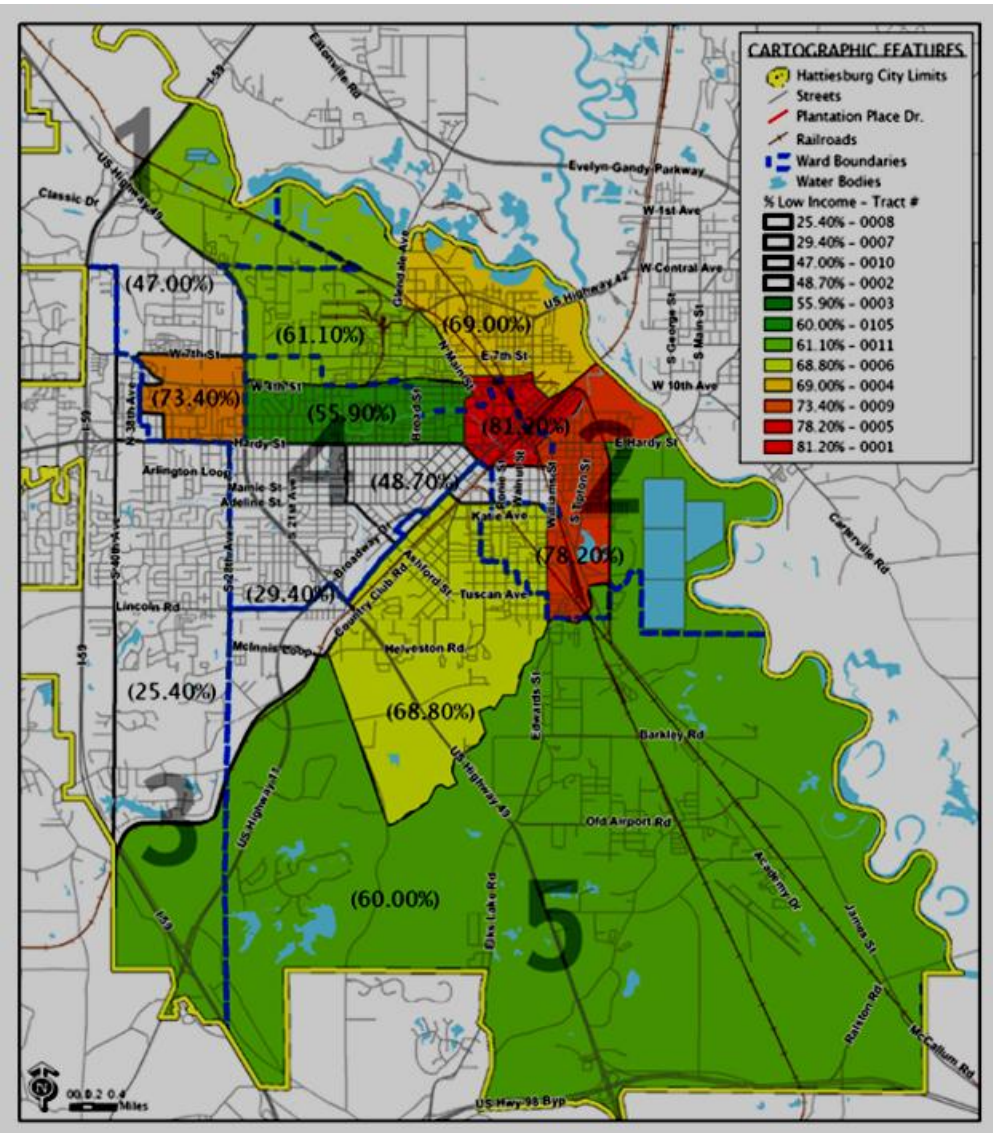

Fig. 1. Distribution of low income areas in the City of Hattiesburg, Mississippi

the project, and at the same time to serve as the liaison between the researchers and the community so that the community needs are reflected effectively in the study protocol.

Ethical procedures: The study was approved by the Institutional Review Board (IRB) of The University of Southern Mississippi, Hattiesburg, Mississippi. The study was conducted according to the guidelines of the Declaration of Helsinki. Informed consent was obtained from all subjects before they were enrolled in the study. In addition, written approval was obtained from the school authorities for the educational classes offered in schools.

Project goals, activities, and measurable outcomes: The primary goals of the research included: 1) Encourage health promotion by conducting community-based outreach (such as health fairs, distribution of educational materials, and public appearances) concerning childhood lead poisoning prevention; and 2) Encourage health promotion by conducting community-based educational andtraining activities (such as seminars, workshops, and classroom or online training) on childhood lead poisoning prevention. The project activities, the specific project outputs, and the measureable outcomes for each activity are narrated in Table-1.

\section{Results}

Population at-risk of lead poisoning: secondary data

Racial difference: Among the 42,372 children who had BLL measured, African-Americans outnumbered the whites ( $84 \%$ vs. $16 \%$, respectively, $p<0.001$ ). The proportion of African-Americans with elevated levels of blood lead was also higher than that of whites $(5.6 \%$ vs. $3.1 \%, p<0.001)$. According to the 2000 census, African-Americans comprise $47 \%$ of the Hattiesburg population. 
Table-1: Project goals, activities, and measureable outcomes

\begin{tabular}{|c|c|c|}
\hline Activity & Specific output & Measureable outcome \\
\hline \multicolumn{3}{|l|}{ Goal 1: Outreach Activities } \\
\hline $\begin{array}{l}\text { Provide health education materials, } \\
\text { educational training, and } \\
\text { presentations to community-based } \\
\text { organizations, child-care centers, } \\
\text { and faith-based communities. }\end{array}$ & $\begin{array}{l}\text { Participate in } 10 \text { health fairs; } \\
\text { disseminate } 600 \text { educational } \\
\text { materials; and make } \\
\text { presentations to } 10 \text { local } \\
\text { community-based partner } \\
\text { organizations. }\end{array}$ & $\begin{array}{l}\text { At post-test, } 90 \% \text { of these } \\
\text { participants are able to (a) Identify } \\
\text { three primary sources of lead in } \\
\text { the environment (paint, dust, and } \\
\text { soil); (b) Identify lead as a poison } \\
\text { found in the environment and } \\
\text { demonstrate a minimum of two } \\
\text { behaviors which will help prevent } \\
\text { lead poisoning; and (c) Identify a } \\
\text { minimum of three complications } \\
\text { (behavioral, physical, and } \\
\text { psychological) of lead poisoning. }\end{array}$ \\
\hline
\end{tabular}

Partner with local home-builder retail stores (such as Home Depot and Lowe's) to host hands-on training on lead poisoning prevention.

Encourage all realtors to take the U.S. Department of Housing and Urban Development (HUD)'s free online Lead-Based Paint Visual Assessment Training.
Conduct two training sessions on lead poisoning prevention and lead-safe home repairs (one in each facility).

75 Hattiesburg realtors would complete the online training.
At least $50 \%$ report that the hands-on training is useful for the prevention from lead contamination.

$90 \%$ of participants report that they use information obtained in the training.

Goal 2: Training Activities

Conduct home-buyer education Conduct 12 home-buyer classes that include curriculum on education classes that include lead poisoning prevention. curriculum on lead poisoning prevention; and yearly home maintenance education course.
At post-test, $75 \%$ of these participants are able to (a) Identify three primary sources of lead in the environment (paint, dust, and soil); (b) Identify lead as a poison found in the environment and demonstrate a minimum of two behaviors which will help prevent lead poisoning; and (c) Identify a minimum of three complications (behavioral, physical, and psychological) of lead poisoning.

At least $75 \%$ of participants will report at follow-up survey that they have used information obtained during the training.
Provide intensive training on lead-
safe work practices to inspectors, contractors, and Do-lt-Yourself (DIY) workers.
Train at least 3 inspectors, 25 contractors, and 25 DIY workers on the 8-h U.S. Department of Housing and Urban Development (HUD) curriculum on lead. 
Provide training in lead-safe work practices and compliance with Toxic Substances Control Act (TSCA) Section 1018 to rental property

Hold at least one seminar for rental property owners on lead-safe work practices.

owners.

Table-2: Outcome of outreach and training activities offered by the CLAP for Healthy Kids program

\begin{tabular}{|c|c|c|}
\hline Target population & $\begin{array}{l}\text { Training activities and training } \\
\text { materials used }\end{array}$ & Outcome \\
\hline General population & $\begin{array}{l}\text { Outreach activities - information } \\
\text { and education, materials given } \\
\text { out; arrange health fair, appear at } \\
\text { community events, neighborhood } \\
\text { meetings, and meeting with the } \\
\text { City Mayor. }\end{array}$ & $\begin{array}{l}\text { 1. The number of participants at } \\
\text { health fairs were } 467 \text {; } \\
\text { 2. } 1000 \text { educational flyers and } \\
\text { brochures on lead prevention were } \\
\text { distributed at health fairs. } \\
\text { 3. The CLAP staff appeared at } 25 \\
\text { community events in which } 469 \\
\text { people participated. } \\
\text { 4. The City Mayor proclaimed the } \\
\text { CLAP for Healthy Kids activities. }\end{array}$ \\
\hline $\begin{array}{l}\text { School children aged 3-5 } \\
\text { years and teachers }\end{array}$ & $\begin{array}{l}\text { Outreach activities - show videos, } \\
\text { and provide pictogram, color } \\
\text { charts, and activity books. }\end{array}$ & $\begin{array}{l}\text { 1. } 241 \text { students attended the class } \\
\text { activities. Students were shown } \\
\text { Sesame Street Lead Away Video } \\
\text { [16]. } \\
\text { 2. A Teacher's Guide to How Mother } \\
\text { Bear Taught the Children about } \\
\text { Lead [17]. } \\
\text { 3. Students received a certificate of } \\
\text { participation. }\end{array}$ \\
\hline General population & $\begin{array}{l}\text { Outreach: Hands-on training at } \\
\text { homebuilding retail stores (Home } \\
\text { Depot and Lowe's). }\end{array}$ & $\begin{array}{l}25 \text { participants showed up at the } \\
\text { homebuilding retail stores training. } \\
\text { Of them, } 23(92 \%) \text { reported that } \\
\text { the hands-on training was very } \\
\text { useful or useful on a Likert scale of } \\
1 \text { to } 5 \text {. }\end{array}$ \\
\hline $\begin{array}{l}\text { Home buyers and retail } \\
\text { home owners }\end{array}$ & $\begin{array}{l}\text { Training workshops offered at the } \\
\text { Neighborhood } \\
\begin{array}{lr}\text { Meetings. } & \text { Association } \\
\text { presentations } & \text { PowerPoint } \\
\text { curriculum on lead } & \text { included } \\
\text { prevention. } & \end{array}\end{array}$ & $\begin{array}{l}90 \% \text { ( } n=91 \text { ) of the participants } \\
\text { mentioned that the training was } \\
\text { useful or very useful on a Likert } \\
\text { scale of } 1 \text { to } 5 \text {. }\end{array}$ \\
\hline
\end{tabular}

At follow-up, $60 \%$ or more of the participants will report they use the information presented at the seminar. 


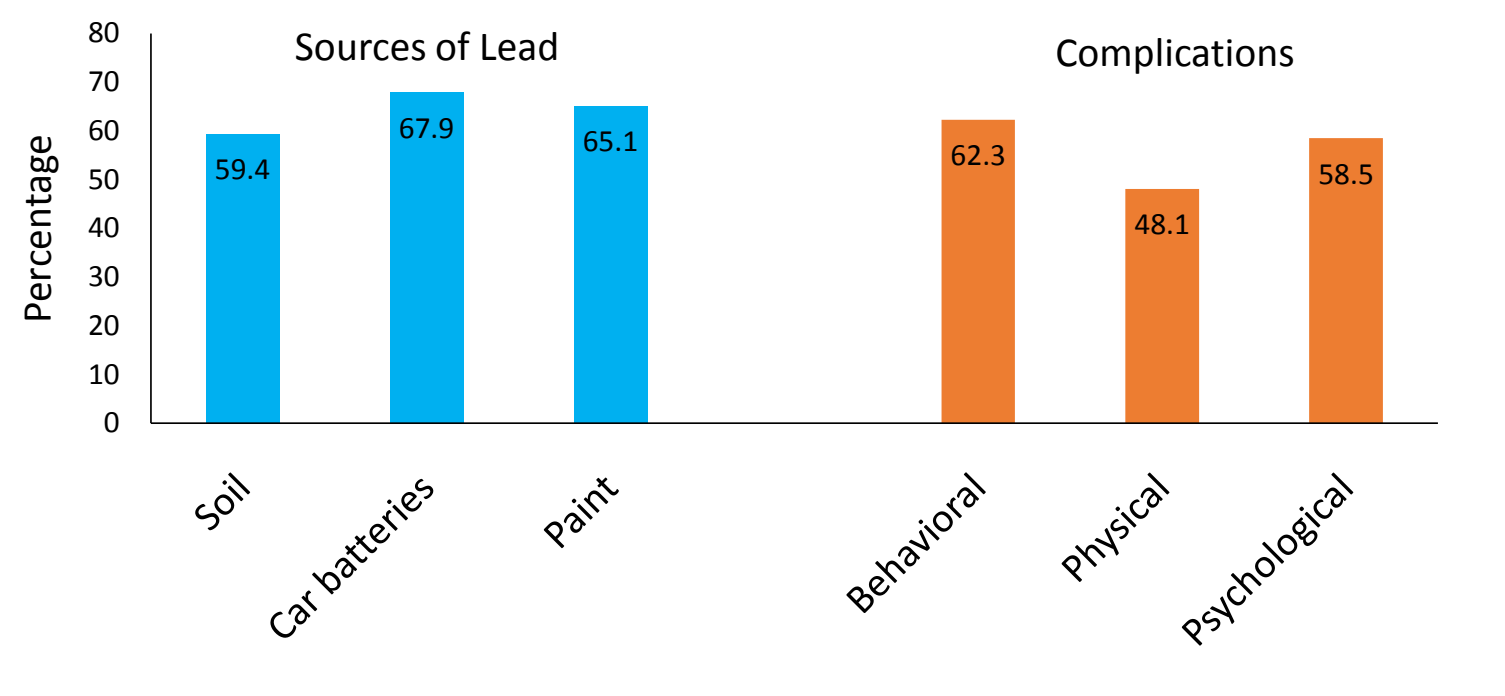

Fig.2: Sources and complications of lead, as idenfied correctly by workers after an online training

Relation between BLL and pre-1978 housing: The 2000 census data was used to calculate the percent of pre-1978 housing units in each county in the state. There was a statistically significant correlation between BLL and percent of housing units $>50$ years old, although the correlation was very weak ( $r=0.10, p<0.001)$. In Hattiesburg, Mississippi, $60 \%$ of residential structures were built prior to 1978 . Members of racial minority groups reside in the majority of these pre-1978 housing structures.

Relation between BLL and income: Again, the 2000 census data at the county level has indicated that the median household income was inversely but weakly correlated with BLL $(r=-0.12, p<0.001)$. Similarly, BLL was inversely correlated with the median rent $(r=-0.086, p<0.001)$ and median value of the house $(r=-0.091, p<0.001)$, meaning the poor were at higher risk of lead poisoning. On average, $26 \%$ of Mississippi children live below the national poverty level.

\section{Training activities and outcomes}

A list of the target population, a summary of the training activities and training materials used, and the outcomes are presented in Table-2. The assessment instruments were: (1) Exit survey for participants for hands-on training at home builder retail stores -10 questions on a scale from 0 to 10 ; (2) Follow-up survey for HUD's Online Training for Realtors -6 questions on a scale from 0 to 10 ; (3) Pre- and posttest of training of home buyers -5 questions; and (4) HUD Curriculum for Inspectors, Contractors, DIY Workers -8 questions.

\section{Impact of online visual training}

Environment Protection Agency/U.S. Department of Housing and Urban Development (EPA/HUD)'s online visual training [18] was given to 220 realtors, and 75 inspectors, contractors, and Do-It-Yourself (DIY) workers.

Fig. 2 shows that at posttest, 59.4\%, 67.9\%, 65.1\% of the realtors, inspectors, contractors and DIY workers ( $n=295$ ) identified soil, car batteries and paint as sources of lead in the environment, respectively. Nearly $70 \%$ identified lead as a poison in the environment while $77.5 \%$ and $47.2 \%$ of those surveyed demonstrated two behaviors (such as wash hands frequently and clean dusty areas), which will help prevent lead poisoning. A total of 
$62.3 \%, 48.1 \%$ and $58.5 \%$, at posttest, identified three complications - behavioral, physical and psychological, respectively. The mean posttest score was significantly higher than the pretest scores $(7.47 \pm 2.07$ vs. $6.60 \pm 1.68, p=0.04$ respectively).

All the participants on HUD online training participated at a 2-month follow-up survey. They reported that they actually implemented what they had learned during the training on HUD curriculum on lead poisoning prevention. The outcome measurements of home-buyer workshops were not significantly different from those of the online training.

\section{Discussion}

Based on the secondary data analysis, this study identified a few areas in Mississippi where $20 \%$ to $27 \%$ of children from low-income (Medicaid eligible) families were found with increased BLLs. The CDC guidelines define an area in the United States as being at high-risk if $12 \%$ or more of the children tested are found with high BLLs [19]. Based on the guideline of the CDC [19], the observed BLLs in children in certain areas of Mississippi put them and the areas they reside at "high-risk". When the Mississippi data are compared with another large cross-sectional study conducted in Bangladesh by Mitra and colleagues [20], the situation of Bangladesh was much worse. Several areas in Dhaka and its neighborhood, especially school-children from Tongi industrial area (99\% with high BLLs) and from Tannery industrial area in Zigatola, Dhaka (91\% with high BLLs) were identified having alarmingly high risk of lead poisoning in Bangladesh. Although the risk of lead poisoning in the United States is mainly from sources such as lead-based paint and dust [3], multiple potential sources of lead poisoning in Bangladesh were identified, including environmental contamination due to industries, discharges from brick kiln factories, hazardous waste dumping in open garbage disposal places in the city, environmental contamination by discharges from tannery industries, air pollution from car repair shops, the use of lead-based paints in potteries and houses, and the use leadcontaining indigenous (kabiraji and homeopathic) medicinal treatments [20]. Another recent study reported a dangerously high level of lead in turmeric which was adulterated with lead based paint (which is yellow) to make them more attractive before they are sold in retail markets in Bangladesh [21]. Immediate steps are needed to regulate and stop human-made lead contaminations of the environment and adulteration of food in Bangladesh and other developing countries.

The CBPR project, CLAP for Healthy Kids, achieved its goal in improving people's awareness and practices in lead prevention in Mississippi through a comprehensive approach of outreach and training activities. A total of 1,588 participants were involved in the outreach and training activities through the project including health fairs, community events, kindergarten school-based training, HUD's online free Lead-Based Paint Visual Assessment Training [18], hands-on training, workshops, and public presentations.

EPA's Renovation, Repair, and Painting (RRP) Rule requires that firms performing renovation, repair, and painting projects use certified renovators who are trained by EPA-approved training providers and follow lead-safe work practices [22]. The training programs of this project were, therefore, in alignment with the EPA/HUDS's objective of encouraging sustainable infrastructure development programs for the prevention of childhood lead poisoning.

Although the outreach programs and trainings were attended by a large number of people, the number of participants at home-building retail stores was not satisfactory. This is a lesson learned that the training programs offered through retail stores such as Lowe's and Home Depot may not be suitable because of people's busy schedules and limited time in spending for hands-on training during shopping. One of the most successful of all programs was the EPA/HUD's online free LeadBased Paint Visual Assessment Training [18]. The reason of success of this program was probably because people had flexibility of scheduling their time for the online training. It is noteworthy that the outcome measurements of home-buyer faceto-face workshops were not significantly different from those of the online training. 
One of the strengths of this study was the community engagement from the beginning of the study in the planning, goal setting, project activities, and project evaluation. The project activities were boost up by the proclamation of the Honorable Mayor of The City of Hattiesburg. CBPR and engagement of the community people have been emphasized in many studies for the success of a community-based program [23]. The project also helped in the sustainability of the lead prevention program in the City by providing training of the home inspectors, DIY workers, realtors, home buyers, and the general people.

Similar success stories of educational programs were reported from another communityparticipatory research in Philadelphia involving 1200 children and 900 adults [24]. In the later study, community-developed strategies were created for this project with resident leaders from the community and grassroots agencies serving the community. The grassroots agencies included the Philadelphia Housing Authority Tenant Councils for Norris Homes and Apartments and Fairhill Apartments; the Village of the Arts and Humanities, an organization devoted to introducing the arts and humanities to all socioeconomic groups; the Philadelphia Parent Child Center; the Neighborhood Action Bureau, an economic development corporation; and the Salvation Army.

Another community-based Tribal Efforts Against Lead (TEAL) project used a lay health advisor model to build capacity in a Native American community to reduce lead exposure in a mining area in northeastern Oklahoma [25]. In the TEAL project, approximately 40 tribal members were recruited from area tribes and trained on lead poisoning and its prevention. For a 2-year period, they educated members of their social networks and worked to implement change in their community to reduce exposure to lead.

One of the limitations of the present study was that it focused on health education only. Although several studies have shown successes in improving education of the people, education alone has a limited effectiveness in alleviating the burden of lead poisoning, especially if it is not combined with resources to actually correct lead-based paint hazards in housing or take remedial measures for other sources of lead poisoning. Studies that evaluated the effectiveness of parents' education alone have failed to show significant reductions in childhood BLLs [26]. Studies are needed to focus on reducing the sources of childhood lead exposures rather than identifying children who have already been unduly exposed or attempting to ameliorate the toxic effects of lead exposure.

\section{Conclusion}

This CBPR was successful in improving people's knowledge in identifying sources of lead, complications, and prevention of lead. The involvement of kindergarten students in learning about lead and its prevention using Sesame Street Lead Away videos [16] was exemplary, and easy-toadopt in other programs. Free online HUD visual lead training programs [18] can be adopted in lead abatement programs in Bangladesh. Countries like Bangladesh should adopt policies following the CDC guidelines for mandatory lead screening of all children under 6 years of age before they are entered to the school. More innovative methods of interventions are needed addressing the needs of high-risk populations and local communities for alleviating the risk of lead poisoning in the community.

\section{Acknowledgments:}

The authors are indebted to Joel Downey, a Home Specialist and a certified home owner instructor for Housing Alternatives in Hattiesburg, Inc. (HAH) for his contribution in identifying community partners, and in providing support in outreach activities of the project.

\section{Funding:}

This research was funded by the National community-based lead outreach and training grant, Environmental Protection Agency, Award No. EPAOPPT-08-003.

Conflicts of interest: The authors declare no conflict of interest. 


\section{References}

1. Centers for Disease Control and Prevention. Blood lead levels in children. Available online: https://www.cdc.gov/nceh/lead/docs/leadlevels-in-children-fact-sheet-508.pdf (accessed on January 1, 2021).

2. Centers for Disease Control and Prevention. CDC national childhood blood lead surveillance data. Available online: https://www.cdc.gov/nceh/lead/data/national .htm (accessed on January 1, 2021).

3. Agency for Toxic Substances \& Disease Registry. Lead toxicity. Who is at risk of lead exposure? Available online: https://www.atsdr.cdc.gov/csem/csem.asp?cs em=34\&po=7 (accessed on January 1, 2021).

4. U.S. Department of Housing and Urban Development. American healthy homes survey-lead and arsenic findings. Available online:

https://www.hud.gov/sites/documents/AHHS_ REPORT.PDF (accessed on 22 December 2020).

5. Centers for Disease Control and Prevention. Preventing lead poisoning in young children; CDC: Atlanta, GA, USA, 2005. Available online: www.cdc.gov/nceh/lead/publications/PrevLea dPoisoning.pdf (accessed on 12 December 2020).

6. Agency for Toxic Substances \& Disease Registry. Toxicological profile for lead. Available online: https://www.atsdr.cdc.gov/ToxProfiles/tp.asp? $\mathrm{id}=96 \& \mathrm{tid}=22$ (accessed on 22 December 2020).

7. Greig J, Thurtle N, Cooney L, Ariti C, Ahmed AO, Ashagre T, Meredith C. Association of blood lead level with neurological features in 972 children affected by an acute severe lead poisoning outbreak in Zamfara State, Northern Nigeria. PLoS ONE. 2014; 9: e93716.

8. Kuang W, Chen Z, Shi K, Sun H, Li H, Huang L, Bi J. Adverse health effects of lead exposure on physical growth, erythrocyte parameters and school performances for school-aged children in eastern China. Environ In. 2020; 145: 106130.
9. Geier DA, Kern JK, Geier MR. Blood lead levels and learning disabilities: A cross-sectional study of the 2003-2004 National Health and Nutrition Examination Survey (NHANES). Int $J$ Environ Res Public Health. 2017; 14: 1202.

10. Hauptman M, Stierman B, Woolfe AD. Children with autism spectrum disorder and lead poisoning: diagnostic challenges and management complexities. Clin Pediatr. 2019; 58: 605-612.

11. Zimmerman E, Borkowski C, Clark S, Brown P. Educating speech-language pathologists working in early intervention on environmental health. BMC Med Educ. 2018; 18: 155.

12. Santa Maria MP, Hill BD, Kline J. Lead $(P b)$ neurotoxicology and cognition. Appl Neuropsychol Child. 2019; 8: 272-293.

13. Mitra AK, Haque A, Islam M, Bashar S. Lead poisoning: an alarming public health problem in Bangladesh. Int J Environ Res Public Health. 2009; 6: 84-95.

14. U.S. Department of Health and Human Services. Office of disease prevention and health promotion. Healthy people 2030. Available online: https://health.gov/healthypeople (accessed on 13 December 2020).

15. Mitra AK, Anderson-Lewis C. Community engagement and outreach programs for lead prevention in Mississippi. Int J Environ Res Public Health. 2021; 18: 202.

16. Prudential Foundation. Sesame street lead away video. Available online: https://video.search.yahoo.com/yhs/search? $\mathrm{fr}=\mathrm{yhs}$-avast-securebrowser $\&$ himp=yhssecurebrowser\&hspart=avast\&p=Sesame+Stre et+Lead+Away+Video\#id=1\&vid=fa96193dfd 22 1 faac764df6ffb47eda2\&action=click (accessed on 13 December 2020).

17. University of Connecticut; Cooperative Extension System; College of Agriculture and Natural Resources. A teacher's guide to how mother bear taught the children about lead. Available online: https://kids.niehs.nih.gov/assets/docs/teacher s_guide_508.pdf\#: :text=How\%20Mother\%20 Bear\%20Taught\%20the\%20Children\%20about 
\%20Lead\%3A,individually\%2C\%20in\%20small\% 20groups\%2C\%20or\%20as\%20a\%20class (accessed on 13 December 2020).

18. U.S. Department of Housing and Urban Development (HUD). Lead based paint visual assessment training course. Available online: https://apps.hud.gov/offices/lead/training/vis ualassessment/h00101.htm (accessed on 10 December 2020).

19. Screening for elevated blood lead levels. American Academy of Pediatrics Committee on Environmental Health. Pediatrics. 1998; 101(6): 1072-1078.

20. Mitra AK, Ahua E, Saha P. Prevalence and risk factors for lead poisoning among young children in Bangladesh. J Health Pop Nutr. 2012; 30(4): 404-409.

21. Forsyth JE, Nurun Nahar S, Islam SS, Baker M, Yeasmin D, Islam MS, et al. Turmeric means "yellow" in Bengali: lead chromate pigments added to turmeric threaten public health across Bangladesh. Environ Res. 2019; 179 (Part A).
22. Environment Protection Agency. Lead Outreach, Partnerships and Grants. Lead Renovation, Repair and Painting (RRP) Rule. Available online: https://archive.epa.gov/epa/lead/leadoutreach-partnerships-and-grants.html (accessed on 13 December 2020).

23. Lasker RD, Weiss ES. Broadening participation in community problem solving: A multidisciplinary model to support collaborative practice and research. J Urban Health 2003; 80: 14-60.

24. Rothman NL, Lourie RJ, Gaughan J. Lead awareness: North Philly style grant team. Am J Public Health. 2002; 92:739-741.

25. Kegler MC, Malcoe LH, Lynch R, WhitecrowOllis S. A community-based intervention to reduce lead exposure among Native American children. Environ. Epidem Toxicol. 2000; 2: 121-132.

26. American Academy of Pediatrics. Prevention of childhood lead toxicity. Pediatrics. 2016; 138: e20161493. 